\title{
Impact of tax increases on illicit cigarette trade in Mongolia
}

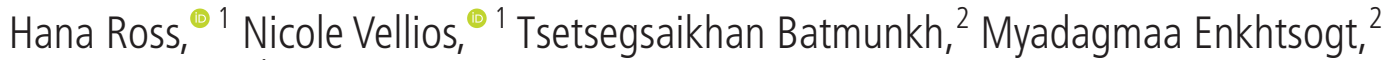 \\ Laura Rossouw ${ }^{1}$
}

- Additional material is published online only. To view please visit the journal online (http://dx.doi.org/10.1136/ tobaccocontrol-2018-054904).

${ }^{1}$ Economics of Tobacco Control Project, School of Economics, University of Cape Town, Cape Town, South Africa

${ }^{2}$ National Cancer Council of Mongolia, Ulaanbaatar, Mongolia

\section{Correspondence to}

Nicole Vellios, Economics of Tobacco Control Project, School of Economics, University of Cape Town, Cape Town, 7700, South Africa; nicole.vellios@uct.ac.za

Received 20 December 2018 Revised 8 April 2019 Accepted 16 April 2019

\section{Check for updates}

(C) Author(s) (or their employer(s)) 2019. No commercial re-use. See rights and permissions. Published by BMJ.

To cite: Ross H, Vellios N, Batmunkh T, et al. Tob Contro/ Epub ahead of print: [please include Day Month Year]. doi:10.1136/ tobaccocontrol-2018-054904

\section{ABSTRACT}

Background The Mongolian government increased import tobacco tax by 30\% in May 2017 and excise tobacco tax by $10 \%$ in January 2018 . To assess the impact of these tax increases on illicit cigarette trade, we estimate illicit trade before and after tax increases. Methods Discarded cigarette packs were collected in the capital city and in two provinces near China, the Russian Federation and Kazakhstan. Tax increases occurred between all three rounds (April 2017, August/ September 2017, May/June 2018). Cigarette packs are identified as illicit if there is evidence that tax was not paid. This is deduced from the absence of the Mongolian excise tax stamp, or the absence of traces of a tax stamp (glue residue). Data are weighted to represent the areas sampled.

Results In round 1, $15.4 \%$ (95\% Cl $14.6 \%$ to $16.2 \%$ ) of the 7494 collected packs were illicit. This estimate decreased to $13.6 \%(95 \% \mathrm{Cl} 12.7 \%$ to $14.5 \%)$ in round 2 (5852 collected packs) and to $6.3 \%(95 \% \mathrm{Cl}$ $5.7 \%$ to $6.9 \%$ ) in round 3 (6258 collected packs). Illicit cigarettes originated primarily from the Republic of Korea and Ukraine, but some were manufactured in Mongolia. While the majority of illicit products are supplied by global companies (Korea Tobacco \& Ginseng, Imperial Tobacco and Philip Morris Kazakhstan), one local company, Mongol Tobacco SO, is also implicated. Conclusions The share of illicit cigarettes declined between rounds 1 and 2 despite the import tax increase, and this trend continued in round 3 despite the excise tax increase.

\section{INTRODUCTION}

Smoking prevalence is high in Mongolia, most likely influenced by the cultural norms of its neighbours, the Russian Federation and China, where smoking is a widespread habit. A 2013 STEPwise approach to Surveillance survey reported that about $49.1 \%$ of males and 5.3\% of females in Mongolia aged 15-64 years were current tobacco users, while $45.4 \%$ of adult males and $4.5 \%$ of adult females were daily smokers. ${ }^{1}$ Smokers use manufactured cigarettes since the sale of loose tobacco products to make roll-your-own cigarettes is banned. ${ }^{2}$

The cigarette market was estimated in 2015 to be approximately 150 million packs per year. ${ }^{3}$ This equates to 70 packs per adult per year, or 4 cigarettes per day for any adult Mongolian. According to 2013 data, Mongolian smokers consume, on average, 10 cigarettes per day. ${ }^{1}$ Of these, about $25 \%$ are produced domestically and $75 \%$ are imported. ${ }^{4}$ The market is relatively consolidated with one local cigarette manufacturer and six cigarette importers. ${ }^{4}$
To deal with the smoking epidemic, Mongolia adopted a relatively progressive set of tobacco control policies in 2012.5 The law requires large pictorial health warnings on packs with text in the local language and smoke-free public places. Cigarette sales are not permitted within $500 \mathrm{~m}$ of schools, dormitories, kindergartens or hospitals. Mongolia also earmarks $1 \%$ of tobacco tax, $1 \%$ of alcohol tax and 2\% of tax from the sale of medicines for a health promotion fund which finances public awareness and education campaigns, the treatment of tobacco dependence, research on the social and economic harms caused by tobacco use, and other health promotion projects. ${ }^{2}$

In 2012, Mongolia significantly increased cigarette excise taxes. ${ }^{5}$ The excise taxes on domestic and imported cigarettes increased by $300 \%$ and $100 \%$, respectively, bringing the excise tax to US $\$ 0.48$ per pack, independent of the origin, plus $10 \%$ Value Added Tax (VAT). ${ }^{5}$ This uniform specific excise tax was initially levied in US\$ to guard against inflation. The tax increase resulted in cigarette prices near doubling, from an average of MNT685 (US\$0.49) to MNT1275 (US\$0.92). Between 2012 and 2013, cigarette sales declined by $17.5 \%$ and real excise tax revenue increased by $88 \%{ }^{6}$

However, this positive trend ended in January 2015 when the government decided to convert the excise tax to the local currency. The conversion should have amounted to MNT900 per pack, but instead the tax was set at MNT696 (US\$0.37) per pack. This tax cut resulted in lost tax revenue, which decreased from MNT134.8 billion in 2014 to MNT104.3 billion in $2015 .{ }^{6}$ At the same time, the tobacco companies generated extra profit by keeping cigarette prices more or less constant. ${ }^{78}$ By 2017 , the value of the tax in US\$ further deteriorated to US\$0.30 per pack even though the tax in MNT did not change.

This tobacco tax policy placed Mongolia among the countries with the lowest tax-to-price ratio in WHO's Western Pacific region, where Mongolia belongs administratively. ${ }^{79}$ The tax in Mongolia represents only $31 \%$ of the retail price although the regional average is $53 \% .^{10}$ As well as a low average tax-to-price ratio, Mongolia also has a wide range of cigarette prices. In July 2017, domestic brands sold for about MNT1500 (US\$0.63), while imported brands sold for about MNT4800 (US\$2.02). ${ }^{11}$ Cigarettes have become more affordable in Mongolia over the past few years. In 2012, smokers needed $4.3 \%$ of their per capita Gross Domestic Product (GDP) to buy 100 cigarette packs of an imported brand, which decreased to $4.1 \%$ in 
2015 and dropped further to $3.9 \%$ in 2016 . The affordability of local brands is about half of the imported brands, even though the imported brands are more popular.

As part of a debt restructuring agreement with the International Monetary Fund, Mongolia agreed to increase excise taxes gradually from 2017 to 2020: 10\% in January 2018, 5\% in January 2019 and $5 \%$ in January $2020 .{ }^{12}$ In addition, there was a sixfold increase in cigarette import taxes in May 2017 when the rate went from $5 \%$ of cost, insurance and freight (CIF) to $30 \%$ of CIF. The import tax increase was proportionally much larger than the excise tax increase that was implemented in January 2018. The ministry of finance (MoF) was expecting the prices of imported cigarettes to increase by MNT300 (US\$0.12) per pack as a result of this tax hike. However, the prices increased by only MNT100-MNT200, depending on the brand, as the importers undershifted the tax. ${ }^{13}$ The undershifting was confirmed by the consumer price index (CPI) of imported cigarettes, proxied by a popular imported cigarette brand, Mevius. The price of Mevius cigarettes increased by $5.9 \%$ from December 2016 to December 2017 , a period during which general inflation was 7.2\%. ${ }^{14-16}$

The January 2018 excise tax increase should have raised the prices by MNT77 (US\$0.03) per pack on average, ${ }^{13}$ but prices increased by MNT200-MNT1200 (US $\$ 0.08-U S \$ 0.5$ ) as the tobacco companies overshifted the tax. ${ }^{17}$ The CPI of the Mevius brand increased by $8.8 \%$ from December 2017 to February 2018, while general inflation was only $2.4 \%$ in that period. By February 2018, an imported pack cost MNT3500-MNT5000 (US\$1.40-US\$2.10). ${ }^{14-17}$

One of the arguments used by the tobacco industry and some policymakers against more substantial tobacco tax increases is the threat of illicit cigarettes. Mongolia implemented several measures to control tax evasion. All tobacco growers, manufacturers, importers and sellers must be licensed, and all tobacco products must have an excise tax stamp, indicate the country of origin, manufacturer/importer, manufacturing date and permission to sell in Mongolia. The tax department of the MoF is responsible for printing and selling excise stamps to domestic manufacturers, while the customs department of the MoF manages importers. Manufacturers order stamps from the tax authority in Mongolia and export the stamps abroad where stamps are affixed to cigarette packs in their production facility. During customs clearance, packs are inspected for the presence of tax stamps and pictorial warnings. Therefore, all legally imported cigarettes will have tax stamps. Both tax and import departments of the MoF enforce the tax law.

Despite concerns about the illicit trade of cigarettes in Mongolia, its scope and relationship to tobacco tax policy is unknown. The scientific literature generally agrees that tobacco taxes are not the main driver of illicit trade in tobacco products. ${ }^{18-20}$ The goal of this study is to assess the extent of tobacco tax avoidance and evasion in Mongolia as a proxy for the size of the illicit cigarette market and to investigate the illicit market's changes in response to a tobacco tax increase.

\section{METHODS}

We employed one of the methods, described in Ross (2015), ${ }^{21}$ that relies on the examination of discarded cigarette packs collected on the ground. This method was selected as one can distinguish whether a pack was intended for the Mongolian market or not by observing a pack's features. The advantage is its objectivity, as the method does not rely on information provided by consumers, who may have incentives to disguise their consumption of illicit products. In addition, it is a relatively

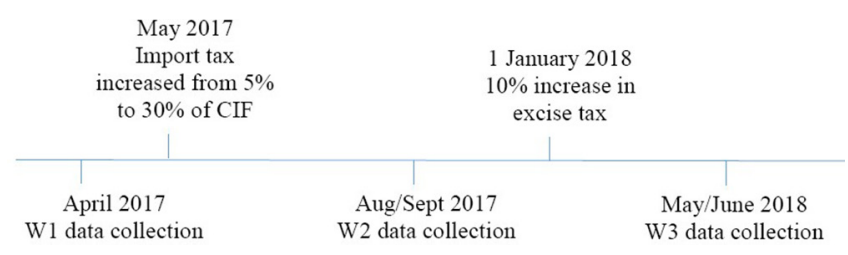

Figure 1 Timeline of tax increases and data collections. CIF: cost, insurance and freight.

simple method to execute at a reasonable cost. Throughout this paper, we will refer to a pack as illicit if there is evidence that no tax was paid in Mongolia.

We designed our study around an expected decision of the Mongolian parliament to increase cigarette taxes in 2017/2018. The goal was to estimate the size of the illicit cigarette market before and after tax increases in order to evaluate the impact of tax policy. Since we encountered two tax increases in a relatively short period of time (May 2017 and January 2018), we collected data in three rounds: the baseline in April 2017, and rounds 2 and 3 in August/September 2017 and May/June 2018, respectively (figure 1)

Discarded packs were collected in the most populated area: the capital city of Ulaanbaatar, where about one-third of the total Mongolian population reside. We also collected packs in two border provinces, Bayan-Ölgii and Dornod (close to the Russian Federation, China and Kazakhstan), to examine whether proximity to a border plays a role in the size and/or composition of the illicit cigarette market. The theory we wanted to test is whether border areas are more susceptible to illicit trade compared to the inland capital city. Bayan-Ölgii and Dornod both have active border crossings with frequent movement of people and goods. Bayan-Ölgii province borders Kazakhstan, the location of the main tobacco importer; Dornod province borders China, where cigarette illicit trade might be prevalent.

While it is possible that some people buy cigarettes across the borders in the allowed quantity (this legal activity is known as tax avoidance), we are identifying illegal activities aimed at paying less tax or no taxes (tax evasion). ${ }^{22}$ The duty-free limits for Mongolia are rather standard (200 cigarettes and 50 cigars and $250 \mathrm{~g}$ of tobacco). Given the limited opportunity for Mongolians to travel abroad, we do not except that many of the illegal cigarettes identified in our study would come from this source.

We calculated a minimum sample size of 1536 packs per wave for $\leq 2 \%$ margin of error and $95 \%$ CI, assuming that illicit packs represent $20 \%$ of the littered packs. Because pack collection is very cost efficient, we oversampled in every round to ensure power.

To obtain a random sample of packs, we used geographical divisions. Ulaanbaatar is divided into nine districts, and these consist of 152 administrative units ('Khoroos'). Dornod and Bayan-Ölgii provinces have 10 and 13 administrative units ('Baghs'), respectively. We designated Khoroos or Baghs as our primary sampling units (PSU). For a detailed description of how the weights were calculated, see online appendix 2 .

Based on the assumption that each PSU could generate a total of about 80 packs, we needed to collect packs from 50 Khoroos, and an additional Khoroo was selected in order to make sure the quota was reached. The number of Khoroos to be surveyed within a district was determined proportional to population size. The specific Khoroos were then randomly selected. Given the low population density outside Ulaanbaatar, all 23 Baghs in Bayan-Ölgii and Dornod provinces were sampled with a goal of finding, on average, 130 packs per Bagh. 
A common starting point for pack collection in each Khoroo/ Bagh was, in most cases, the main market/shopping centre. A team of two fieldworkers began pack collection in the vicinity of the starting point going in all possible directions. As research has shown that littered packs do not differ systematically from properly disposed-of empty packs, ${ }^{23} 24$ fieldworkers collected packs either on the ground or at the top of waste bins.

Fieldworkers stopped when they reached a distance from the starting point where no additional packs were found. If the team had not reached the quota of $80 / 130$ packs, they continued to another starting point in the same Khoroo/Bagh. This would generally be the second-largest market or shopping centre or, in a few cases where no second market was available, a restaurant or bar. The teams were instructed to walk up to 5 hours in each Khoroo/Bagh in order to reach the quota. In some cases, the team had to return to the same Khoroo/Bagh the next day to reach the quota.

Round 1 fieldworkers kept a detailed diary of their routes and took pictures of the points of departure so that the fieldworkers in rounds 2 and 3 could follow the same routes. Rounds 1, 2 and 3 data collection generated 7494, 5852 and 6258 packs, respectively. More packs were collected in round 1 because of weather conditions. Round 1 occurred in last winter month of April when the snow was melting. In the winter months, there is more garbage on the streets as the presence of snow restricts regular garbage collection. Rounds 2 and 3 were collected in summer months when garbage collection occurs more frequently.

Each collected pack was labelled with a different colour sticker according to the district/province and assigned a unique ID number that identified the specific location and collection date. Online appendix 1 lists all the variables captured for each pack.

A schematic presentation of the classification and prevalence of illicitly traded cigarette packs is presented in online appendix 3. A cigarette pack is primarily considered illicit if there is no Mongolian tax stamp. Since smokers often remove the tax stamp because it obstructs access to the cigarettes in a pack, we looked for glue residue that would indicate that the stamp had been removed. All packs with glue residue (298 in round 1, 255 in round 2 and 395 in round 3) comply with the Mongolian packaging laws (pictorial warnings: $50 \%$ on the back and front of the packs, and health warnings in the Mongolian language). We found very few instances where packs had a Mongolian tax stamp but did not comply with pictorial warning and language requirements (four in round 1 , six in round 2 and one in round 3). These packs were still considered legal, as they comply with our definition of licit trade (tax paid to Mongolian government). Packs with a foreign tax stamp are considered illicit as no tax was paid in Mongolia.

Ten per cent of the data describing the packs' attributes were double coded by a second data capturer to cross verify data entry (round 1: 771 packs; round 2: 508 packs; round 3: 659 packs). Any discrepancies between the first and second data capturer were assessed by a third person. Overall, no changes were made to round 1 data, 17 changes to round 2 data and 8 changes to round 3 data. Of these, 13 changes were made to tax stamp data (presence of tax stamp or signs of a tax stamp) entries in round 2 and 7 in round 3 . In order to generate results representing the entire sampled areas, we calculated poststratification weights by multiplying the inverted probabilities of selecting a Khoroo/Bagh and a pack, taking into account the smoking prevalence and the average number of cigarettes smoked per day by a smoker. Descriptive analyses are used to describe sample characteristics. Postestimation t-tests are used to test the statistical significance of changes over the three rounds.

\section{RESULTS}

Estimates of the share of illicit cigarettes using unweighted and weighted data revealed that the share of illicit cigarettes decreased slightly between rounds 1 and 2, with a weighted illicit trade prevalence of $15.40 \%$ (95\% CI $14.59 \%$ to $16.22 \%$ ) and $13.61 \%$ (95\% CI $12.73 \%$ to $14.49 \%$ ), respectively (table 1 ). The decrease is statistically significant at the $5 \%$ level $(p=0.03)$. By the third round (after the second tax increase), the share of illicit cigarettes dropped by almost half to 6.33\% (95\% CI 5.72\% to $6.93 \%)$, a statistically significant decline $(\mathrm{p}=0.00)$. Overall, covering a period where two tax increases occurred, there was a 9.07 percentage point decline in illicit trade $(p=0.00)$. The weighted and unweighted results are very similar.

The decrease in the illicit market share in the third round occurred in all sampled provinces, but the effects are more pronounced in Ulaanbaatar and Bayan-Ölgii (table 1). Between rounds 1 and 3 , the weighted share of illicit packs declined from $15.42 \%$ (95\% CI $14.34 \%$ to $16.51 \%$ ) to $6.25 \%$ (95\% CI $5.54 \%$ to $6.95 \%$ ) in Ulaanbaatar and $15.53 \%$ (95\% CI $13.75 \%$

Table 1 Prevalence of illicit cigarette packs before and after tax increases (weighted vs unweighted)

\begin{tabular}{|c|c|c|c|c|c|c|}
\hline & \multicolumn{2}{|l|}{ Round $1(n=7494)$} & \multicolumn{2}{|l|}{ Round $2(n=5852)$} & \multicolumn{2}{|l|}{ Round $3(n=6258)$} \\
\hline & Mean (SE) & Mean (SE) & Mean (SE) & Mean (SE) & Mean (SE) & Mean (SE) \\
\hline & $(95 \% \mathrm{Cl})$ & $(95 \% \mathrm{Cl})$ & $(95 \% \mathrm{Cl})$ & $(95 \% \mathrm{Cl})$ & $(95 \% \mathrm{Cl})$ & $(95 \% \mathrm{Cl})$ \\
\hline & Unweighted & Weighted & Unweighted & Weighted & Unweighted & Weighted \\
\hline \multirow[t]{2}{*}{ Illicit cigarettes } & $14.69 \%(0.41)$ & $15.40 \%(0.42)$ & $13.45 \%(0.45)$ & $13.61 \%(0.45)$ & $6.3 \%(0.31)$ & $6.33 \%(0.31)$ \\
\hline & (13.89\% to $15.49 \%)$ & (14.59\% to $16.22 \%)$ & (12.57\% to $14.32 \%)$ & $(12.73 \%$ to $14.49 \%)$ & (5.69\% to $6.9 \%)$ & $\begin{array}{l}(5.72 \% \text { to } \\
6.93 \%)\end{array}$ \\
\hline \multirow[t]{2}{*}{ Ulaanbaatar } & $15.13 \%(0.55)$ & $15.42 \%(0.55)$ & $13.03 \%(0.54)$ & $13.65 \%(0.55)$ & $6.13 \%(0.36)$ & $6.25 \%(0.36)$ \\
\hline & $(14.06 \%$ to $16.21 \%)$ & (14.34\% to $16.51 \%)$ & (11.98\% to $14.08 \%)$ & (12.58\% to $14.72 \%)$ & (5.43\% to $6.83 \%)$ & $\begin{array}{l}(5.54 \% \text { to } \\
6.95 \%)\end{array}$ \\
\hline \multirow[t]{2}{*}{ Bayan-Ölgii } & $15.89 \%(0.92)$ & $15.53 \%(0.91)$ & $15.09 \%(0.98)$ & $15.33 \%(0.99)$ & $5.33 \%(0.7)$ & $5.56 \%(0.71)$ \\
\hline & (14.09\% to $17.69 \%)$ & (13.75\% to $17.31 \%)$ & $(13.17 \%$ to $17.02 \%)$ & $(13.39 \%$ to $17.27 \%)$ & (3.96\% to $6.71 \%)$ & $\begin{array}{l}(4.16 \% \text { to } \\
6.96 \%)\end{array}$ \\
\hline \multirow[t]{2}{*}{ Dornod } & $12.35 \%(0.82)$ & $14.69 \%(0.88)$ & $12.5 \%(1.38)$ & $11.08 \%(1.31)$ & $8.76 \%(1.06)$ & $9.33 \%(1.09)$ \\
\hline & (10.75\% to $13.95 \%)$ & (12.97\% to $16.42 \%)$ & (9.8\% to $15.2 \%)$ & (8.52\% to $13.65 \%$ ) & (6.67\% to $10.84 \%)$ & $\begin{array}{l}\text { (7.19\% to } \\
11.48 \%)\end{array}$ \\
\hline
\end{tabular}




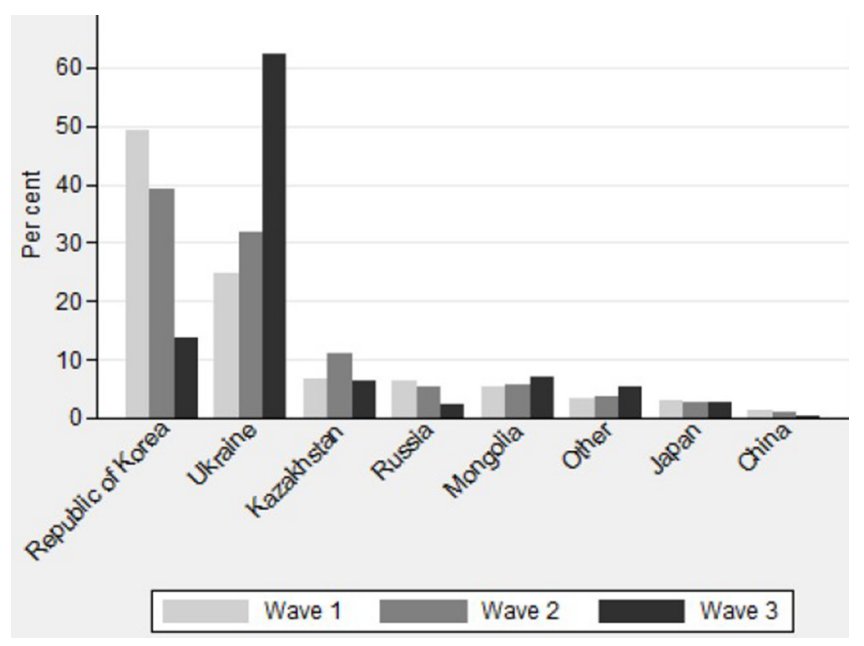

Figure 2 Illicit cigarettes: the most common countries of origin (weighted).

to $17.31 \%$ ) to $5.56 \%$ (95\% CI $4.16 \%$ to $6.96 \%$ ) in Bayan-Ölgii. The decline in Dornod, a province near Kazakhstan border, was much less pronounced (from $14.69 \%$ to $9.33 \%$ ).

Illicit cigarette packs in Mongolia consist predominantly of brands originating from the Republic of Korea (49.14\% of the total illicit market in round 1,39.08\% in round 2 and $13.59 \%$ in round 3$)$, Ukraine $(24.82 \%$ of the total illicit market in round $1,31.88 \%$ in round 2 and $62.46 \%$ in round 3 ) and Kazakhstan (6.74\% of the total illicit market in round 1, 10.91\% in round 2 and $6.23 \%$ in round 3) (figure 2). Packs from neighbouring China $(1.37 \%$ of the total illicit market in round $1,1.11 \%$ in round 2 and $0.19 \%$ in round 3 ) and the Russian Federation (6.24\% of the total illicit market in round $1,5.16 \%$ in round 2 and $2.38 \%$ in round 3 ) are quite rare (figure 2 and online appendix 4).

A disaggregation of illicit trade by manufacturer (figure 3) reveals that the Korea Tobacco \& Ginseng (KT\&G) was the largest manufacturer in round $1(45.22 \%$ of the total illicit market) and 2 (38.68\%), but that Imperial Tobacco replaced $\mathrm{KT} \& \mathrm{G}$ in round $3(62.81 \%)$. Both these companies manufacture outside of Mongolia. The two most common brands of illicit cigarettes (figure 4) were imported Esse Change (KT\&G) and imported West Red (Imperial Tobacco), with a large drop in the

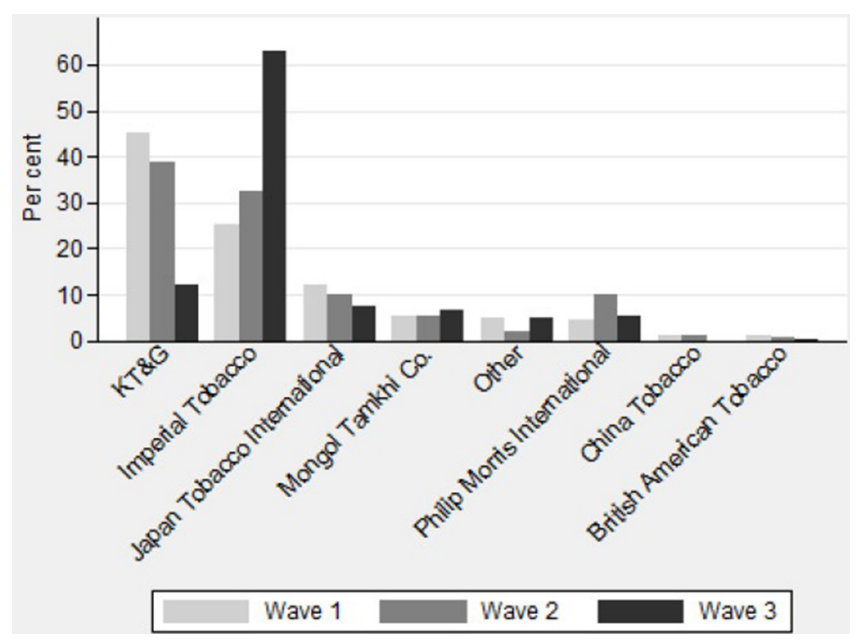

Figure 3 The most common illicit manufacturers (weighted). KT\&G: Korea Tobacco \& Ginseng.

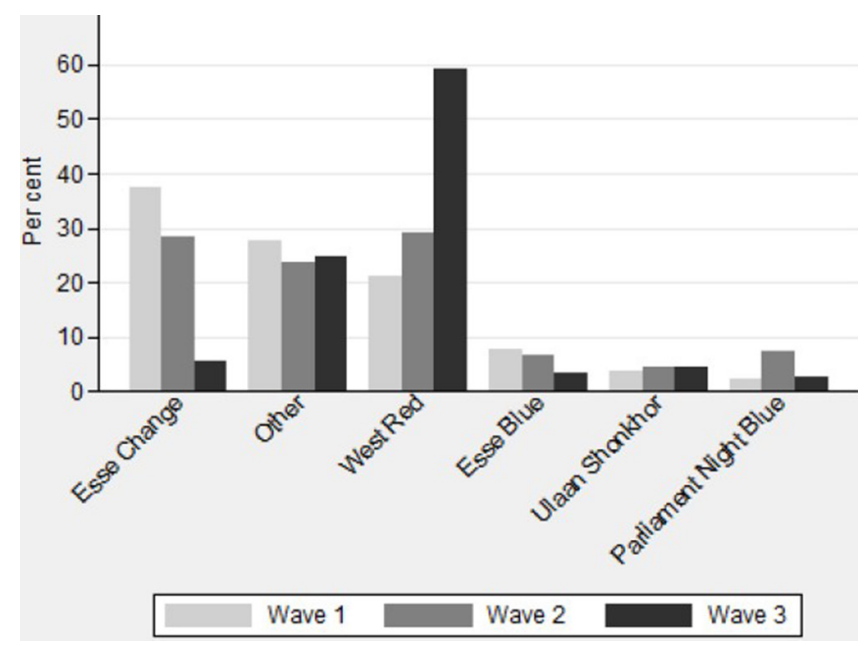

Figure 4 The most common illicit brands (weighted).

share of Esse Change of the total illicit market from $28.55 \%$ in round 2 to $5.43 \%$ in round 3 . However, the decline in the share of the illicit cigarettes on the market would still hold even if we exclude Esse Change from the analysis. The composition of illicit brands across provinces is quite similar.

Online appendix 4 reports the absolute numbers presented in figures 2-4.

\section{DISCUSSION}

We find that the illicit cigarette trade in Mongolia declined after the 2017 and 2018 tobacco tax increases. This confirms findings from other countries suggesting that there is no or only a limited relationship between tobacco tax and the illicit cigarette trade. ${ }^{1820}$ The lower share of illicit cigarettes in the border provinces, and the similar composition of illicit brands across provinces, indicates that proximity to a border does not determine the supply of illicit cigarettes.

The government may want to consider banning duty-free shops in the city, since they could be a source of tax-free cigarettes to the general public, although the instances were few in this sample $(0.12 \%$ in round $1,0.59 \%$ in round 2 and $0.25 \%$ in round 3 -see online appendix 4$)$.

The relatively small tax increases proposed for the years 2018-2020 in Mongolia are insufficient to reach the global sustainable development goals to reduce prevalence by $30 \%$ by the year 2025. ${ }^{25}$ A 2016 study found that for the government of Mongolia to reach this target, it would need to increase excise tax ninefold so that the average price would reach MNT9944 (about US\$5.30) per pack by $2025 .^{26}$ Such an increase would reduce the number of smokers by about 70000 and approximately treble the tobacco tax revenue. ${ }^{26}$

\section{Limitations}

We note several limitations. First, our method cannot distinguish between illicit tax evasion and legal tax avoidance, because a non-compliant pack could have been brought into the country legally (eg, by tourists). Mongolia hosted about 470000 tourists in 2017 (about $15 \%$ of its population size). ${ }^{27}$ Therefore, we may have overestimated the size of illicit cigarette market. Second, our estimates are not nationally representative. However, our estimates represent approximately $52 \%$ of the total population of Mongolia. Third, the sample could be biased because of the areas selected within Khoroos (the second stage of selection). These markets/shopping centres were selected because of the 
likelihood of finding discarded packs on the streets. Although residential areas were not selected, packs from private houses were a part of our sample to the extent that their residents go to shopping centres. Fourth, we were unable to verify the authenticity of tax stamps. Since the presence of tax stamps is used to determine the legality of packs, packs with counterfeit tax stamps would be considered legal in this study, which would result in an overestimation of illicit trade.

\section{CONCLUSION}

This study adds to the growing body of evidence pointing to there being in fact no link between tobacco taxes and the share of illicit cigarettes in the market. Mongolia can, therefore, proceed with strengthening tobacco tax policy without fear of the influx of illicit cigarettes, as is portrayed by the tobacco industry. Nevertheless, the government needs to monitor illicit trade and take decisive action against manufacturers of illicit cigarettes to prevent the illicit supply of cigarettes to the market. We demonstrated the usefulness of a trash collection method for such monitoring, particularly if data are collected regularly from the same locations.

\section{What this paper adds}

- We provide the first independent estimates of the cigarette illicit market in Mongolia before and after tax increases.

- We add to the growing body of evidence demonstrating that tax increases do not drive the illicit cigarette trade.

Acknowledgements We thank J.Michael Bowling from the University of North Carolina at Chapel Hill for assistance with calculating weights. We also thank Battsetseg Tsedevdamba and Lynette Smith from the National Cancer Council of Mongolia for capturing and cleaning the data.

Contributors HR developed the idea for this research and wrote the first draft of the paper. NV assisted with data cleaning, data analysis and writing the paper. TB managed data collection. ME entered and cleaned the data. LR calculated the weights and conducted the data analysis.

Funding Cancer Research UK (IRMA 25171).

Competing interests None declared.

Patient consent for publication Not required.

Provenance and peer review Not commissioned; externally peer reviewed.

Data sharing statement Data are available in a public, open access repository.

\section{REFERENCES}

1 World Health Organization. Third national STEPS survey on the prevalence of noncommunicable disease and injury risk factors - 2013, 2014. Available: http:// www.who.int/ncds/surveillance/steps/Mongolia_2013_STEPS_Report.pdf [Accessed 18 Feb 2019].

2 Government of Mongolia. Law of Mongolia on tobacco control. Chapter 1. General provisions, 2012. Available: https://www.tobaccocontrollaws.org/files/live/Mongolia/ Mongolia\%20-\%20Law\%20on\%20TC.pdf [Accessed 18 Feb 2019].

3 Ministry of Finance of Mongolia. Excise tax on tobacco in Mongolia. Presentation 20 October 2016. Manila, the Philippines.
4 National Statistics Office of Mongolia. Import data 2016.

5 World Health Organization Framework Convention on Tobacco Control Secretariat. Needs assessment for the implementation of the WHO framework convention on tobacco control in Mongolia. September 2015.

6 Blecher E. An evaluation of Mongolian tobacco taxes 2011-2015. Personal communication 2016

7 World Health Organization. Report on the global tobacco epidemic, 2015. Available: http://www.who.int/tobacco/global_report/2015/en/ [Accessed 18 Feb 2019].

8 Government of Mongolia. Data from the Ministry of finance 2016.

9 World Health Organization. Report on the global tobacco epidemic, 2013. Available: http://www.who.int/tobacco/global_report/2013/en/ [Accessed 18 Feb 2019].

10 World Health Organization. Report on the global tobacco epidemic, 2017. Available: http://www.who.int/tobacco/global_report/2017/en/[Accessed 18 Feb 2019].

11 Personal observations by Hana Ross in multiple locations in Mongolia in July 2017.

12 World Health Organization Western Pacific Region. Tobacco and alcohol taxes to gradually increase from 2018 to 2020. Available: http://www.wpro.who.int/mongolia/ mediacentre/releases/20170218-tobacco-and-alcohol-taxes/en/ [Accessed 18 Feb 2019].

13 Personal communication between Hana Ross and Mr. Sanal Enkhbaatar from the Ministry of finance on 20 July 2017.

14 National Statistics Office of Mongolia. Socio-economic status of Mongolia: monthly Bulletin of statistics. Ulaanbaatar: national statistics office report number: 2017/12. Available: http://www.en.nso.mn/content/242 [Accessed 18 Feb 2019].

15 National Statistics Office of Mongolia. Socio-economic status of Mongolia: monthly bulletin of statistics. Ulaanbaatar: National Statistics Office Report number: 2017/12, 2019.

16 National Statistics Office of Mongolia. Social and economic situation of Mongolia (as of February 2018), 2018. Available: http://www.en.nso.mn/content/250 [Accessed 18 Feb 2019]

17 Online prices retrieved by Tsetsegsaikhan Batmunkh 21st February 2018. Available: https://eshop.nomin.mn/foods/khyamdraltai-khudaldaa/tamhi.html?dir=desc\&limit= $10 \&$ mode $=$ list\&order $=$ name

18 Joossens L, Raw M. Turning off the tap: the real solution to cigarette smuggling. Int J Tuberc Lung Dis 2003;7:214-22.

19 Joossens L, Merriman D, Ross $\mathrm{H}$, et al. The impact of eliminating the global illicit cigarette trade on health and revenue. Addiction 2010;105:1640-9.

20 U.S. National Cancer Institute and World Health Organization. The economics of tobacco and tobacco control. National Cancer Institute Tobacco Control Monograph 21. NIH publication No. 16-CA-8029A. Bethesda, MD; Geneva, CH: U.S. Department of Health and Human Services, National Institutes of Health, National Cancer Institute, World Health Organization, 2016

21 Ross H. Understanding and measuring tax avoidance and evasion: a methodological guide. Prepared for the Economics of Tobacco Control Project, School of Economics, University of Cape Town and Tobacconomics, Health Policy Center, Institute for Health Research and Policy, University of Illinois at Chicago, 2015. Available: http://www.tobaccoecon.uct.ac.za/etcp/publications/reports [Accessed 15 Oct 2018].

22 World Bank. Confronting illicit tobacco trade: a global review of country experiences, 2019. Available: http://documents.worldbank.org/curated/en/677451548260528135/ Confronting-Illicit-Tobacco-Trade-a-Global-Review-of-Country-Experiences [Accessed 18 Feb 2019].

23 Merriman D. The Micro-Geography of Tax avoidance: evidence from littered cigarette packs in Chicago. American Economic Journal: Economic Policy 2010;2:61-84.

24 Williams E, Curnow R, Streker P. Understanding littering behavior in Australia. A community change consultants report. Beverage Industry Environment Council. ACN 008542 765. 1997. https://kab.org.au/wp-content/uploads/2012/05/understandinglittering-behaviour-lbs1.pdf [accessed 18 Feb 2019].

25 World Health Organization. Global actionplan for the prevention and control of noncommunicable diseases, 2013-2020, 2013. Available: https://www.who.int/nmh/ events/ncd_action_plan/en/ [Accessed 18 Feb 2019].

26 American Cancer Society. Mongolia tobacco taxes: improving health and economies. How to reduce smoking prevalence using the EHPR model 2016.

27 The National statistical office of Mongolia via CEIC data (SG) PTE LTD. Available: https://www.ceicdata.com/en/indicator/mongolia/visitor-arrivals 